Article

\title{
The Influence of Glass Flake and Micaceous Iron Oxide on Electrochemical Corrosion Performance of Waterborne Silicate Coatings in 3.5\% $\mathrm{NaCl}$ Solution
}

\author{
Xu Zhao, Yuhong Qi *, Zhanping Zhang and Kejiao Li \\ Department of Materials Science and Engineering, Dalian Maritime University, Dalian 116026, China; \\ zx1988@dlmu.edu.cn (X.Z.); zzp@dlmu.edu.cn (Z.Z.); lkj19941128@dlmu.edu.cn (K.L.) \\ * Correspondence: yuhong_qi@dlmu.edu.cn
}

Received: 6 October 2019; Accepted: 1 December 2019; Published: 6 December 2019

\begin{abstract}
Waterborne silicate composite coatings were prepared to replace existing solvent-based coatings for ships. A series of complex coatings were prepared by adding anticorrosive pigments to the silicate resin. Adhesion, pencil hardness, and impact resistance were investigated, and corrosion performance in $3.5 \% \mathrm{NaCl}$ solution was measured by electrochemical impedance spectroscopy (EIS). The results show that adhesion and impact resistance are high, and that pencil hardness can reach $4 \mathrm{H}$. The curing mechanism for the coatings were investigated by Fourier-transform infrared spectroscopy (FTIR) and X-ray diffraction (XRD). The mechanism of curing reaction in the studied waterborne silicate paint was found to be different from that reported in the literature. When the coatings were immersed in $3.5 \% \mathrm{NaCl}$ solution for $8 \mathrm{~h}$, there is only one time constant in the Bode plot, and coating capacitance $\left(Q_{c}\right)$ gradually increases while coating resistance $\left(R_{c}\right)$ gradually decreases. Glass flake composite coatings have better corrosion resistance by comprehensive comparison of $Q_{c}$ and $R_{c}$.
\end{abstract}

Keywords: waterborne inorganic coating; anticorrosion coating; glass flake; micaceous iron oxide; curing mechanism; electrochemical impedance spectroscopy

\section{Introduction}

While ship corrosion in the ocean is inevitable, the corrosion rate can be controlled. Currently, there are two main corrosion protection methods for ships: cathodic protection and coating. Cathodic protection can be achieved by replacing iron corrosion with a metal that is more active than iron. Specific processes [1] include physical vapor deposition, chemical vapor deposition, micro-arc oxidation, and thermal spraying of zinc, zinc-aluminum [2-8], or zinc-magnesium-aluminum [9]. Coating depends primarily on anticorrosion coatings. The more mature coatings are solvent-based anticorrosion coatings. Although their anticorrosion effect is very good, the volatile organic compound produced in the painting process of steel products and their facilities accounts for $20 \%-25 \%$ of the global total [10] and has become the main source of atmospheric pollution. Therefore, it is of practical significance to develop low volatile organic compounds (VOC) emitting waterborne anticorrosion paints replacing solvent-based anticorrosion paints. At present, waterborne anticorrosion paints are still in the development stage and their painting technology and paint performance need to be improved. The commonly studied waterborne anticorrosion paints can be divided into organic and inorganic. Although waterborne organic paints have been widely researched and some progress has been made, the synthesis of waterborne resins is still inseparable from the use of organic volatiles. Contrarily, inorganic paints do not possess organic volatiles and therefore exhibit a better environmental performance. Waterborne inorganic paints are promising substitutes. Waterborne inorganic anticorrosion paints mainly include silicate $[11,12]$, silica sol $[13,14]$, and phosphate paints $[15,16]$. Silicate and silica sol improve adhesion 
between metal and coating [17]. When silicate and silica sol coatings are applied, van der Waals bonds between the resin and substrate are initially produced, and are then transformed into covalent bonds during curing. Silicate and silica sol not only enhance adhesion, but also heighten comprehensive performances [18]. However, cohesion of silica sol paints is larger during polycondensation. This is likely to cause the coatings to crack or lead to large area fall off $[19,20]$. Phosphate paints need high temperature for curing, and their application is limited by the application environment $[19,21]$. Although waterborne silicate coatings possess excellent adhesion and environmental performance, they also possess disadvantages such as poor water resistance and mechanical properties [19,22-26]. These disadvantages can be improved by means of acid modification, organic-inorganic hybridization, and nano-modification [27]. In this paper, the silicate resin modified by nano-sized silicone-acrylic emulsion was investigated. It possesses the advantages of silicone and acrylic resin. The water resistance and mechanical property are improved by silicone and acrylic resin, respectively. Nano-effects enhance the overall performance. Flake anticorrosive pigments, such as micaceous iron oxide (MIO) and glass flake (GF), have been widely used to enhance the corrosion resistance for coatings [28-31]. $\mathrm{SiO}_{2}$ is the main chemical composition of GF that has low water vapor permeability, abrasion resistance, and chemical inertness [32]. MIO is a natural mineral and $\alpha-\mathrm{Fe}_{2} \mathrm{O}_{3}$ is the main chemical composition of MIO. MIO is capable of fracturing into very thin plate-like cleavage fragments [33]. MIO can be distributed in parallel to bring about a "labyrinth effect", which results in the diffusion path of corrosive media within the coating to become more tortuous, thus increasing time for corrosive media to diffuse within the coating, reducing the formation of corrosion galvanic cells, and slowing the corrosion rate [23,32-34]. This has been confirmed by some scholars. For example, Yan et al. [35] confirmed that the highest impedance of the phosphate ceramic coatings was obtained with increased content of GF, and Danaee et al. [36] confirmed that the rate of reactivity of inorganic zinc-rich coatings was reduced when replacing zinc powder with MIO. The addition of GF and MIO not only improves the protective performance but also reduces the curing shrinkage, thereby improving the comprehensive performance of coatings. Therefore, this paper will be focused on the influence of GF and MIO on electrochemical corrosion performance of waterborne silicate coatings in $3.5 \% \mathrm{NaCl}$.

\section{Experiment}

\subsection{Materials}

Wuhan Modern Technologies Institute (China) provided nano-modified waterborne silicate resin for zinc-rich paint (E777-2). Its main constituent is potassium silicate, which has $25 \%$ solid content, 10-12 pH, and 1.02-1.20 g/mL density. Jiangsu Kecheng Nonferrous Metal New Material Co., Ltd. (Taizhou, China) provided the 500 mesh spherical zinc powder. Talc, composite calcium zinc phosphate, titanium dioxide, MIO, and GF were obtained from Dalian Keli Ultrafine Powder Co., Ltd. (China), Wuhan Modern Technologies Institute (China), Shanghai Hongyunyuan Chemical Co., Ltd. (China), Changzhou Lehuan Trading Co., Ltd. (China), and Hebei Quanbao Anticorrosive Material Co., Ltd. (Langfang, China). Tianjin Kemiou Chemical Reagent Co., Ltd. (China) provided triethylamine. The morphology of MIO and GF observed by using a confocal laser scanning microscope (CLSM, OLS4000, Olympus, Tokyo, Japan) is shown in Figure 1, while the radius-thickness ratio and density are shown in Table 1.

Table 1. The radius-thickness ratio and density for MIO and GF.

\begin{tabular}{ccc}
\hline Powder & Radius-Thickness Ratio & Density $\left(\mathrm{g} / \mathrm{cm}^{\mathbf{3}}\right)$ \\
\hline MIO & 2.09 & $4.7-4.9$ \\
GF & 5.47 & 2.5 \\
\hline
\end{tabular}



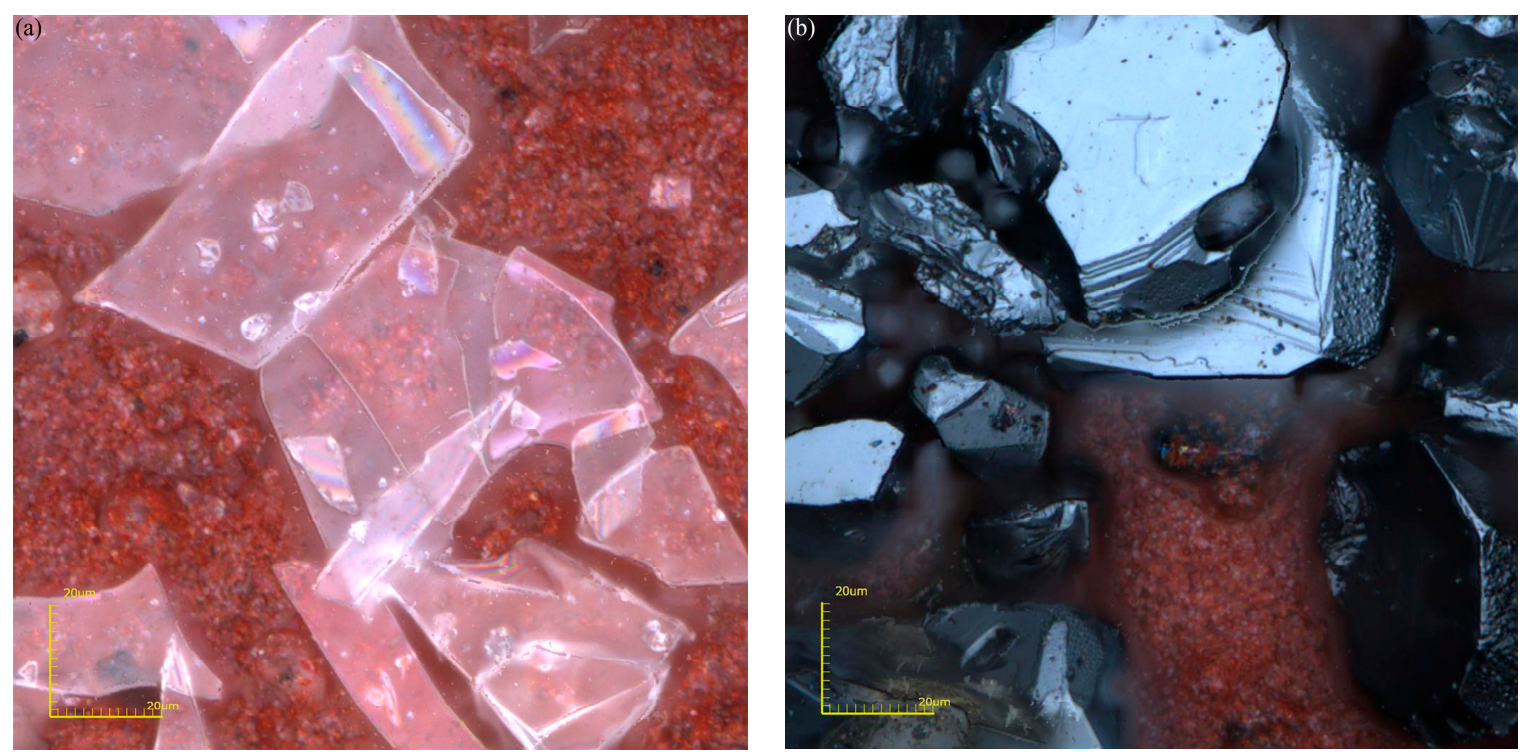

Figure 1. The images of (a) glass flake (GF) and (b) micaceous iron oxide (MIO).

\subsection{Preparation of the Antirust Paint}

\subsubsection{Formulation}

The basic composition (Z5) for the antirust paint is shown in Table 2.

Table 2. The basic composition of the antirust paint.

\begin{tabular}{cc}
\hline Raw Materials (wt.\%) & Z5 \\
\hline E777-2 & 30 \\
500 mesh spherical zinc powder & 70 \\
\hline
\end{tabular}

\subsubsection{Preparation}

E777-2 was poured into a $100 \mathrm{~mL}$ stirring tank with a speed of $500 \mathrm{r} / \mathrm{min}$. Anticorrosive pigment was then added to the tank according to the amount in the formulation, and then the speed was increased to $1500 \mathrm{r} / \mathrm{min}$ while stirring for $15 \mathrm{~min}$.

\subsection{Preparation of GF and MIO Anticorrosion Paint}

\subsubsection{Formulation}

The basic composition of anticorrosion paint is listed in Table 3. G16/M16, G14/M14, G12/M12, G10/M10, and G8/M8 are specimens with 16\%, 14\%, 12\%, 10\%, and 8\% GF/MIO, respectively.

Table 3. The basic composition of GF and MIO anticorrosion paint.

\begin{tabular}{cccccc}
\hline Raw Materials/wt.\% & G16/M16 & G14/M14 & G12/M12 & G10/M10 & G8/M8 \\
\hline E777-2 & 64 & 64 & 64 & 64 & 64 \\
Talc & 4 & 4 & 4 & 4 & 4 \\
Composite calcium zinc phosphate & 5 & 5 & 5 & 5 & 5 \\
Titanium dioxide & 1 & 1 & 1 & 1 & 1 \\
Deionized water & 10 & 12 & 14 & 16 & 18 \\
GF/MIO & 16 & 14 & 12 & 10 & 8 \\
\hline
\end{tabular}




\subsubsection{Preparation}

E777-2 and deionized water were added into a $300 \mathrm{~mL}$ stirring tank, then pigments and fillers were added and stirred at $1500 \mathrm{r} / \mathrm{min}$ for $2 \mathrm{~min}$ after addition of each powder. Finally, an appropriate amount of triethylamine was added, stirring at $1500 \mathrm{r} / \mathrm{min}$ for $15 \mathrm{~min}$.

\subsection{Preparation of Studied Coatings}

For basic mechanical properties testing, each paint was brushed onto aluminum plates. The zinc-rich antirust paints prepared in Section 2.2.2 were brushed onto a steel plate, after which the GF and $\mathrm{MIO}$ anticorrosion paints were brushed onto the antirust coating in order to prepare the composite coatings for electrochemistry and salt spray testing. Each paint was cured for 1 day at $24{ }^{\circ} \mathrm{C}$ at $50 \%-60 \%$ humidity. Since the total salt content of seawater is about $3.5 \%-3.7 \%$ and the salt is mainly $\mathrm{NaCl}$, a $3.5 \% \mathrm{NaCl}$ solution can be used instead of seawater as the corrosion medium. The $3.5 \% \mathrm{NaCl}$ solution has been widely used for corrosion testing. For example, Elahinia et al. [37] used a 3.5\% $\mathrm{NaCl}$ solution to test the potentiodynamic polarization curve of micro-arc oxidation coating.

\subsection{Preparation and Characterization of Specimens}

\subsubsection{Preparation of the Cross Section Specimens}

A specimen with a size of $20 \mathrm{~mm} \times 20 \mathrm{~mm}$ was cut from the Z5/Z5 + G8/Z5 + G14 coating with a saw blade and then fixed with steel splint. Non-cutting edge of the specimen was then sanded with 400-1000 grit sandpaper and polished.

\subsubsection{Characterization}

In order to study the curing mechanism for the silicate paints, the spectra of the resin and film of E7772 were measured by a Frontier PerkinElmer infrared spectrometer (Waltham, MA, USA) with a scan range of $650-4000 \mathrm{~cm}^{-1}$ and a resolution of $2 \mathrm{~cm}^{-1}$. The Z5 specimens prepared in Section 2.5.1 were tested using an X-ray diffractometer (D/MAX-Ultima ${ }^{+}$, Rigaku, Tokyo, Japan) with Co K $\alpha$ radiation and a $10^{\circ}-100^{\circ}$ diffraction angle. In order to study the basic mechanical properties of anticorrosion coatings, we measured the adhesion, pencil hardness, and impact strength using a film adhesion tester (QFZ-II, Tianjin Material Testing Machine Factory, Tianjin, China), a pencil scratch hardness tester (QHQ-A, Tianjin Material Testing Machine Factory), and a paint film impactor (QCJ, Tianjin Yonglida Material Testing Machine Co., Ltd., Tianjin, China) according to GB/T1720-1979 [38], GB/T6739-2006 [39], and GB/T1732-1993 [40]. In order to study the corrosion resistance of composite coatings, the cross section of the coating Z5 + G8/Z5 + G14 was observed by OLS4000 CLSM version 2.2.4 (Olympus, Tokyo, Japan). Z5 + G8, Z5 + G16, Z5 + M8, and Z5 + M16 were performed for a $168 \mathrm{~h}$ salt spray testing on the SFT030 Salt Spray Test Machine (Chongqing Hanba Test Equipment Co., Ltd., Chongqing, China) according to the standard ASTM B117 [41]. EIS of composite coatings immersed in $3.5 \% \mathrm{NaCl}$ was measured by a ZAHNER IM6ex Electrochemical Workstation (Kronach, Germany) with a COLT (Coating \& Laminate Tester) system. The signal amplitude was $10 \mathrm{mV}$ vs. the open circuit potential and the frequency was $1 \mathrm{~Hz}-100 \mathrm{kHz}$. The test operation referred to the reference [42]. The results were treated by Z.03 USB software and then analyzed by ZSimpWin3.2.1 software.

\section{Results and Discussion}

\subsection{Curing Mechanism for Silicate Paints}

Generally, the film curing mechanism for silicate paints obeys the following reaction equations [19,43-45]. In order to verify whether the curing mechanism of the silicate paints in this paper satisfies these reaction equations, the resin and film of E777-2 and the cross section of zinc-rich coating were tested by FTIR and XRD, respectively. The results are shown in Figures 2-4. The absorption bands at around 694, 1445, and $2953 \mathrm{~cm}^{-1}$ are ascribed to out-of-plane bending, in-plane 
bending and stretching vibration of $\mathrm{C}-\mathrm{H}$. The appearance of bands at 756, 1156, 1636, and $1728 \mathrm{~cm}^{-1}$ is attributed to the characteristic absorption of $\mathrm{Si}-\mathrm{C}, \mathrm{C}-\mathrm{O}, \mathrm{C}=\mathrm{C}$, and $\mathrm{C}=\mathrm{O}$, respectively. Moreover, the sharp peaks at 1021, 1046, and $3354 \mathrm{~cm}^{-1}$ correspond to $\mathrm{Si}-\mathrm{OH}, \mathrm{Si}-\mathrm{O}-\mathrm{Si}$, and $-\mathrm{OH}$ in $\mathrm{H}_{2} \mathrm{O}$. The appearance of $\mathrm{Si}-\mathrm{OH}$ can provide direct evidence for Equation (1) and indirect evidence for Equation (2). $\mathrm{Si}-\mathrm{OH}$ and $\mathrm{Si}-\mathrm{O}-\mathrm{Si}$ directly confirm Equation (4). The $\mathrm{Zn}_{2} \mathrm{SiO}_{4}$ in Figure 4 comes from the reaction of the active metal $\mathrm{Zn}$ with ortho silicic acid. However, the appearance of $\mathrm{Zn}_{2} \mathrm{SiO}_{4}$ is inconsistent with Equation (3). Equation (3) reveals that the silicate paints form a silicate during the curing process, but the XRD test results demonstrate that the silicate paints form an orthosilicate during the curing process. Therefore, based on the test results of this paper, we suggest that Equation (3) should be modified. The modified result is shown in Equation (5).

$$
\begin{aligned}
& \mathrm{K}_{2} \mathrm{O} \cdot m \mathrm{SiO}_{2} \cdot n \mathrm{H}_{2} \mathrm{O}+(2 m-n+1) \mathrm{H}_{2} \mathrm{O} \rightleftharpoons 2 \mathrm{KOH}+m \mathrm{Si}(\mathrm{OH})_{4} \\
& 2 \mathrm{KOH}+\mathrm{CO}_{2}+\mathrm{H}_{2} \mathrm{O} \rightarrow \mathrm{K}_{2} \mathrm{CO}_{3}+2 \mathrm{H}_{2} \mathrm{O} \\
& M+\mathrm{H}_{2} \mathrm{SiO}_{3} \rightarrow \mathrm{MSiO}_{3}+\mathrm{H}_{2} \\
& m \mathrm{Si}(\mathrm{OH})_{4} \rightarrow \mathrm{HO}\left(\mathrm{SiO}_{2}\right)_{m} \mathrm{H}+(2 m-1) \mathrm{H}_{2} \mathrm{O} \\
& 2 \mathrm{M}+\mathrm{H}_{4} \mathrm{SiO}_{4} \rightarrow \mathrm{M}_{2} \mathrm{SiO}_{4}+2 \mathrm{H}_{2}
\end{aligned}
$$

where $m, n$ and $M$ respectively are modulus, water content and Fe or Zn.

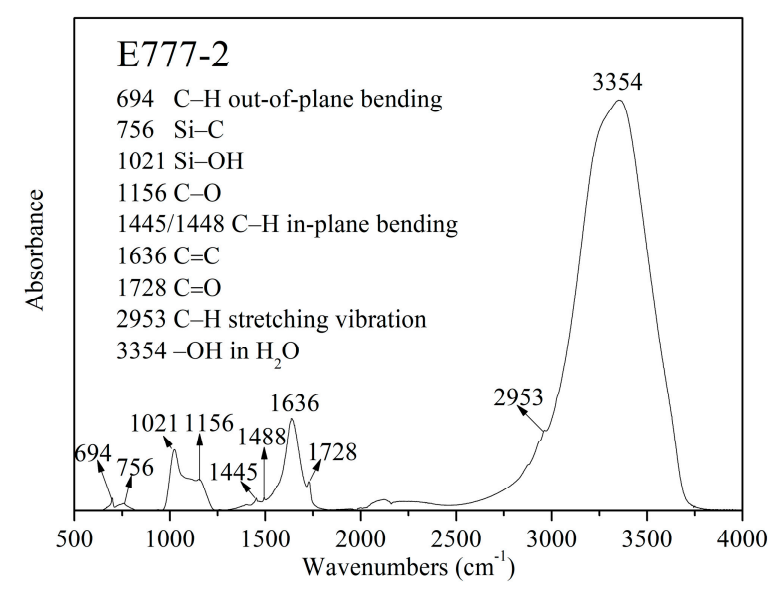

Figure 2. FTIR curve of the E777-2 resin.

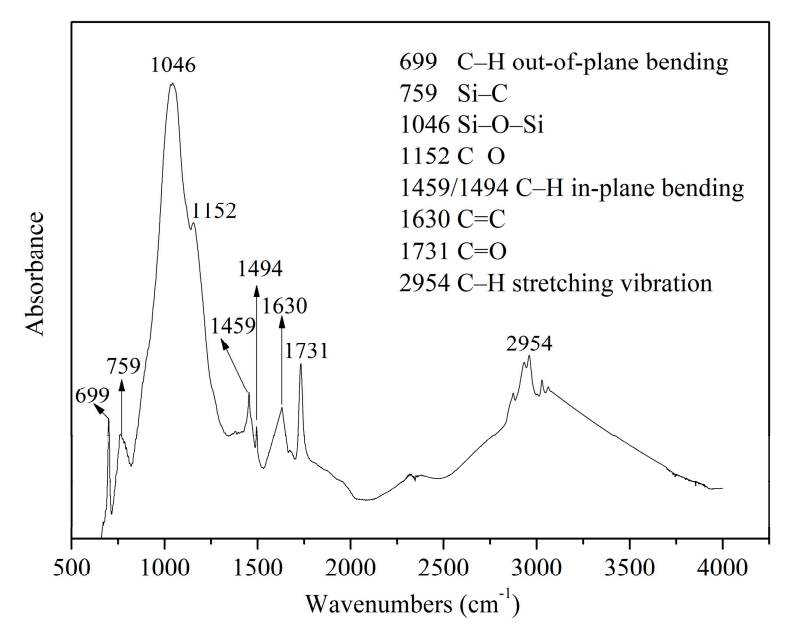

Figure 3. FTIR curve of the E777-2 film. 


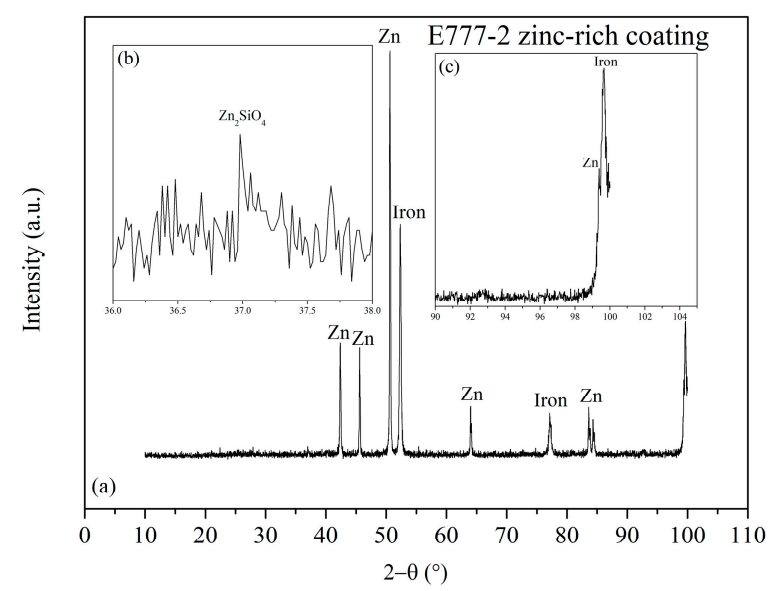

Figure 4. XRD pattern of (a) the antirust coating Z5 and $(\mathbf{b}, \mathbf{c}) \mathrm{Z} 5$ partial magnification.

\subsection{Basic Mechanical Properties for GF and MIO Anticorrosion Coatings}

The basic mechanical properties for GF and MIO anticorrosion coatings are shown in Tables 4 and 5. The adhesion and impact strength are Grade 1 and $50 \mathrm{~kg} \cdot \mathrm{cm}$, respectively, which shows that the added pigments and fillers and their contents did not affect the adhesion of the resin to the substrate and the enwrapping of the resin to the pigments and fillers. The paints form a continuous film after curing. Since stable covalent bonds (Equation (5)) are formed during the drying stage of the films, the coatings exhibit good cohesiveness and flexibility.

Tables 4 and 5 show that pencil hardness increases with the contents of GF and MIO. This shows that the added GF and MIO enhance the scratch resistance of the coatings.

In the case of the same amount of anticorrosive pigment, the pencil hardness of the MIO coating is higher than that of the GF coating (except for $8 \%$ ). This is mainly due to the fact that the hardness of the MIO exceeds that of the GF. After MIO is dispersed into the coating, its reinforcing effect is stronger. Therefore, the scratch resistance of the coating containing MIO is better.

Table 4. Basic mechanical properties for GF anticorrosion coatings.

\begin{tabular}{cccc}
\hline Sample & Pencil Hardness (H) & Adhesion (Grade) & Impact Resistance $\mathbf{( k g \cdot c m ) ~}$ \\
\hline G16 & 3 & 1 & 50 \\
G14 & 2 & 1 & 50 \\
G12 & 2 & 1 & 50 \\
G10 & 2 & 1 & 50 \\
G8 & 2 & 1 & 50 \\
\hline
\end{tabular}

Table 5. Basic mechanical properties for MIO anticorrosion coatings [43].

\begin{tabular}{cccc}
\hline Sample & Pencil Hardness (H) & Adhesion (Grade) & Impact Resistance (kg.cm) \\
\hline M16 & 4 & 1 & 50 \\
M14 & 3 & 1 & 50 \\
M12 & 3 & 1 & 50 \\
M10 & 3 & 1 & 50 \\
M8 & 2 & 1 & 50 \\
\hline
\end{tabular}

\subsection{Anticorrosion Performance of Composite Coatings}

The EIS of composite coatings immersed in $3.5 \% \mathrm{NaCl}$ were measured at 1, 2, 4, 6, and $8 \mathrm{~h}$. Z5 + G16 and Z5 + M16 results are shown in Figures 5 and 6, and the remaining results are shown in Appendix A. 


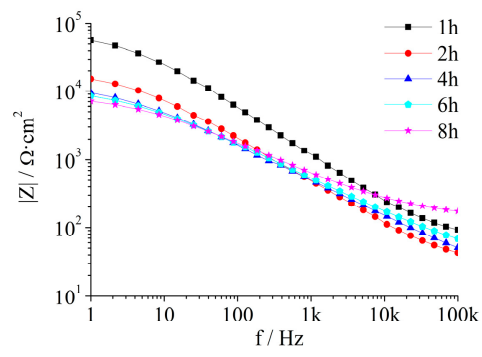

(a)

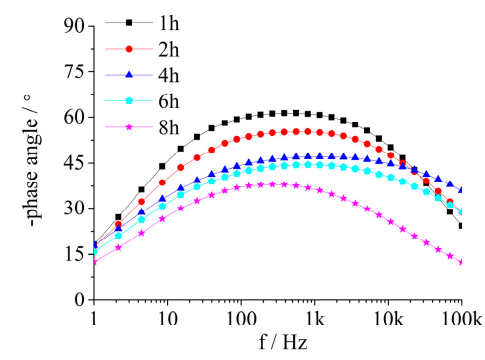

(b)

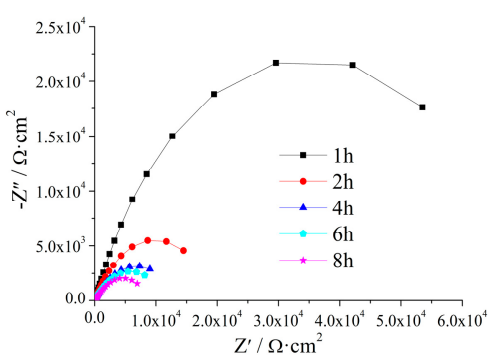

(c)

Figure 5. Bode (a,b) and Nyquist (c) plot of Z5 + G16 in 3.5\% NaCl.

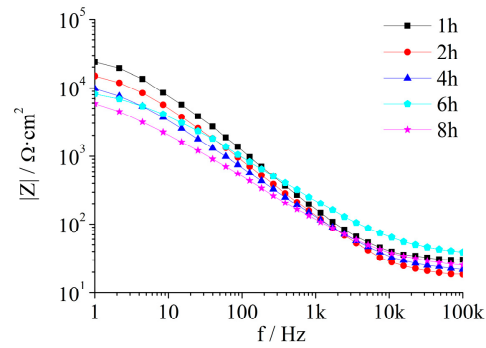

(a)

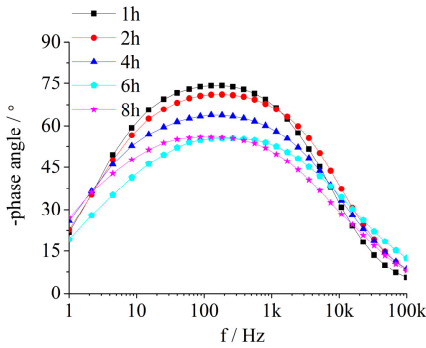

(b)

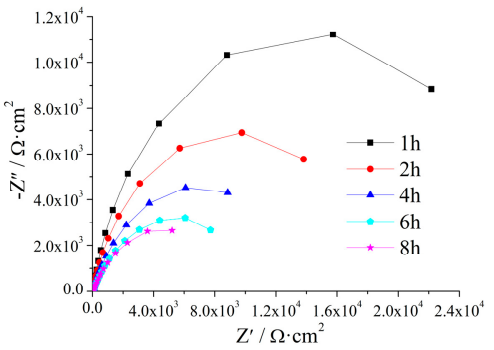

(c)

Figure 6. Bode (a,b) and Nyquist (c) plot of Z5 $+\mathrm{M} 16$ in $3.5 \% \mathrm{NaCl}$.

It can be seen form Figures $5 \mathrm{a}, \mathrm{b}$ and $6 \mathrm{a}, \mathrm{b}$ that each Figure $5 \mathrm{a}$ or Figure $6 \mathrm{a}$ is essentially a diagonal, and there is only one peak in Figures $5 \mathrm{~b}$ and $6 \mathrm{~b}$. This indicates that the composite coatings have only one time-constant impedance spectrum. In other words, the $3.5 \% \mathrm{NaCl}$ solution does not reach the antirust coating over $8 \mathrm{~h}$. Moreover, the composite coatings can also maintain good corrosion resistance in a 168 h salt spray environment (Figure 7). Consequently, compared with some conventional coatings such as waterborne modified epoxy [46] and polyurethane coating [47], the composite coatings prepared in this paper have better protection properties.

Figures $5 c$ and $6 c$ indicate that the capacitive loop decreases with immersion time. It can be seen from Figures $5 a, b$ and $6 a, b$ that with extension of time the low frequency impedance reduces, the impedance-frequency curve moves toward the low frequency, and the phase angle curve descends and moves toward the high frequency. These reveal that $Q_{c}$ increases but $R_{c}$ decreases as time increases, which indicates that corrosive media gradually diffused towards the interior of composite coatings.

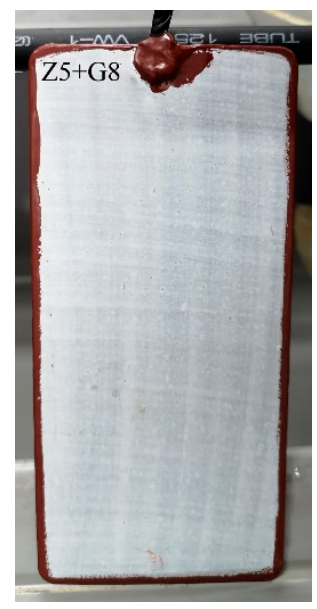

(a)

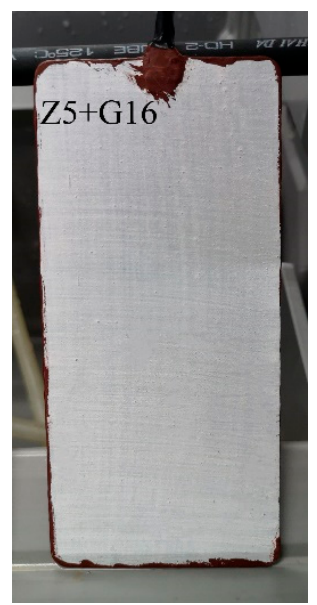

(b)

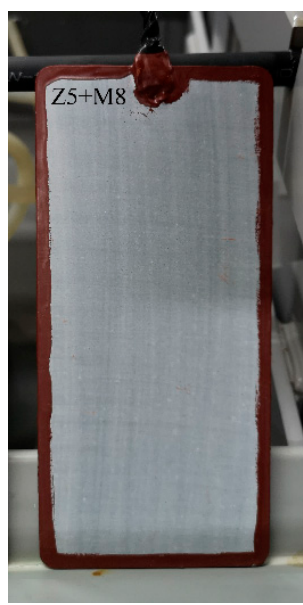

(c)

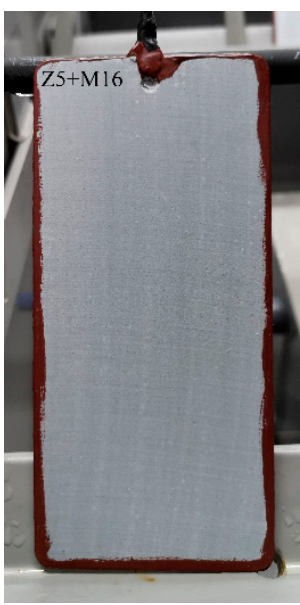

(d)

Figure 7. Cont. 


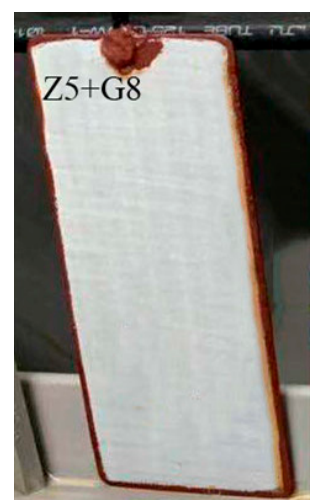

(e)

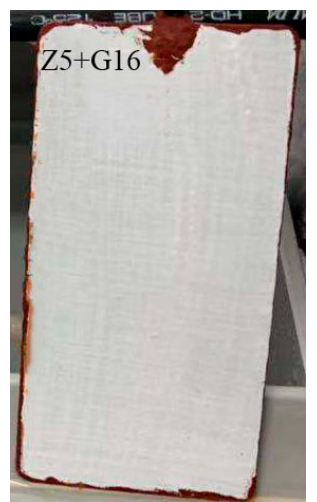

(f)

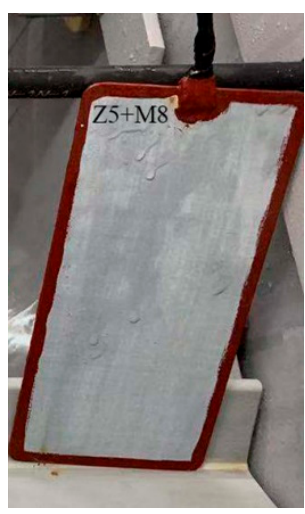

(g)

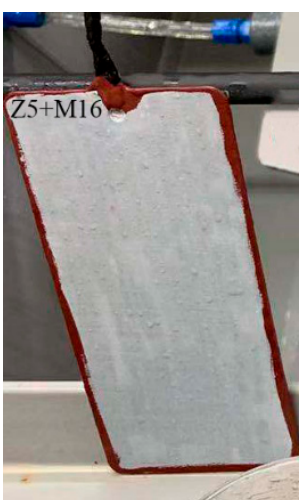

(h)

Figure 7. The morphology of composite coatings before and after salt spray tests according to ASTM B117: (a-d) 0 h; (e-h) 168 h.

The results shown in Figures 5 and 6 were analyzed by the equivalent circuit $R(Q R)$ (Figure 8 ) and the fitted results are shown in Tables 6 and 7.

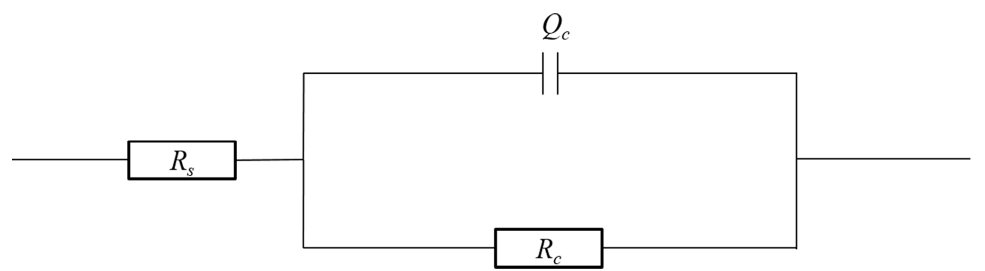

Figure 8. Circuit used to fit the EIS data, where $R_{S}$ is solution resistance.

Table 6. Electrochemical parameters of GF composite coatings immersed in 3.5\% NaCl.

\begin{tabular}{|c|c|c|c|c|}
\hline Sample & Time (h) & $Q_{c}\left(\mu \mathrm{F} \cdot \mathrm{cm}^{-2} \cdot \mathrm{Hz}^{1-n}\right)$ & $n$ & $R_{c}\left(\mathrm{k} \Omega \cdot \mathrm{cm}^{2}\right)$ \\
\hline \multirow{5}{*}{$\mathrm{Z} 5+\mathrm{G} 8$} & 1 & 3.365 & 0.8018 & 22.29 \\
\hline & 2 & 3.572 & 0.7511 & 9.49 \\
\hline & 4 & 14.62 & 0.7045 & 9.265 \\
\hline & 6 & 15.44 & 0.65 & 8.672 \\
\hline & 8 & 21.1 & 0.6857 & 7.024 \\
\hline \multirow{5}{*}{$\mathrm{Z} 5+\mathrm{G} 10$} & 1 & 3.975 & 0.779 & 29.97 \\
\hline & 2 & 5.208 & 0.7529 & 9.848 \\
\hline & 4 & 6.87 & 0.6962 & 9.587 \\
\hline & 6 & 8.918 & 0.7643 & 8.886 \\
\hline & 8 & 9.851 & 0.7795 & 7.466 \\
\hline \multirow{5}{*}{$\mathrm{Z} 5+\mathrm{G} 12$} & 1 & 3.704 & 0.7574 & 33.86 \\
\hline & 2 & 3.786 & 0.7343 & 16.18 \\
\hline & 4 & 3.845 & 0.6935 & 10.56 \\
\hline & 6 & 15.71 & 0.678 & 9.344 \\
\hline & 8 & 19.16 & 0.6294 & 8.579 \\
\hline \multirow{5}{*}{$\mathrm{Z} 5+\mathrm{G} 14$} & 1 & 3.591 & 0.7523 & 35.38 \\
\hline & 2 & 3.693 & 0.6584 & 17.38 \\
\hline & 4 & 15.56 & 0.7038 & 12.91 \\
\hline & 6 & 15.66 & 0.5714 & 10.96 \\
\hline & 8 & 20.56 & 0.6527 & 8.898 \\
\hline \multirow{5}{*}{$\mathrm{Z} 5+\mathrm{G} 16$} & 1 & 1.639 & 0.7171 & 69.92 \\
\hline & 2 & 6.861 & 0.6543 & 19.46 \\
\hline & 4 & 15.6 & 0.5545 & 13.82 \\
\hline & 6 & 16.36 & 0.5421 & 11.91 \\
\hline & 8 & 17.41 & 0.5278 & 9.319 \\
\hline
\end{tabular}


Table 7. Electrochemical parameters of MIO composite coatings immersed in $3.5 \% \mathrm{NaCl}$.

\begin{tabular}{|c|c|c|c|c|}
\hline Sample & Time (h) & $Q_{c}\left(\mu \mathrm{F} \cdot \mathrm{cm}^{-2} \cdot \mathrm{Hz}^{1-n}\right)$ & $n$ & $R_{c}\left(\mathrm{k} \Omega \cdot \mathrm{cm}^{2}\right)$ \\
\hline \multirow{5}{*}{$\mathrm{Z} 5+\mathrm{M} 8$} & 1 & 2.668 & 0.8705 & 17.81 \\
\hline & 2 & 6.725 & 0.82 & 9.349 \\
\hline & 4 & 9.02 & 0.7831 & 6.051 \\
\hline & 6 & 13.83 & 0.7384 & 5.753 \\
\hline & 8 & 15.76 & 0.713 & 5.323 \\
\hline \multirow{5}{*}{ Z5 + M10 } & 1 & 3.935 & 0.888 & 19.18 \\
\hline & 2 & 11.28 & 0.8077 & 9.495 \\
\hline & 4 & 27.93 & 0.7375 & 8.614 \\
\hline & 6 & 31.29 & 0.6843 & 8.412 \\
\hline & 8 & 34.35 & 0.7067 & 7.178 \\
\hline \multirow{5}{*}{ Z5 + M12 } & 1 & 3.311 & 0.8706 & 20.63 \\
\hline & 2 & 7.635 & 0.8054 & 13.45 \\
\hline & 4 & 18.09 & 0.7432 & 9.883 \\
\hline & 6 & 18.13 & 0.7113 & 9.317 \\
\hline & 8 & 38.54 & 0.6806 & 7.686 \\
\hline \multirow{5}{*}{$\mathrm{Z} 5+\mathrm{M} 14$} & 1 & 2.352 & 0.8681 & 26.64 \\
\hline & 2 & 5.505 & 0.7937 & 17.2 \\
\hline & 4 & 10.72 & 0.7794 & 12.51 \\
\hline & 6 & 11.87 & 0.6689 & 10.03 \\
\hline & 8 & 12.39 & 0.7099 & 8.872 \\
\hline \multirow{5}{*}{ Z5 + M16 } & 1 & 3.181 & 0.8664 & 27.75 \\
\hline & 2 & 5.698 & 0.8255 & 18.16 \\
\hline & 4 & 11.84 & 0.7499 & 13.48 \\
\hline & 6 & 12.32 & 0.6824 & 10.55 \\
\hline & 8 & 25.41 & 0.6776 & 8.98 \\
\hline
\end{tabular}

The change of $Q_{c} / R_{c}$ in evaluating the protective performance over time is shown in Figures 9 and 10 . For each content of anticorrosive pigment, $Q_{c}$ gradually increases but $R_{c}$ gradually decreases as the time is extended. At the early stage of corrosion, water absorption and the porosity of the coating increase due to the penetration of water as well as of aggressive particles, and $Q_{c}$ is proportional to water absorption [48] and $R_{c}$ is inversely proportional to coating porosity, so $Q_{c}$ gradually increases while $R_{c}$ gradually decreases as corrosion progresses. At the same time, the coatings that have higher anticorrosive pigment content possess a larger $R_{c}$. Due to the fact that defects as well as the coating porosity gradually decrease while the "labyrinth effect" is gradually enhanced (Figures 11 and 12), the content of anticorrosive pigments gradually increases. The GF composite coating has a larger $R_{c}$ and a smaller $Q_{c}$ in cases where the immersion time and the content of the anticorrosive pigment are the same. This is due to the following facts. On the one hand, the radius-thickness ratio of GF (5.47) is larger than that of MIO (2.09). On the other hand, in cases where the content of the anticorrosive pigment is the same, the volume of GF in the coating is larger than that of MIO in the coating since the density of GF is smaller than that of MIO. 


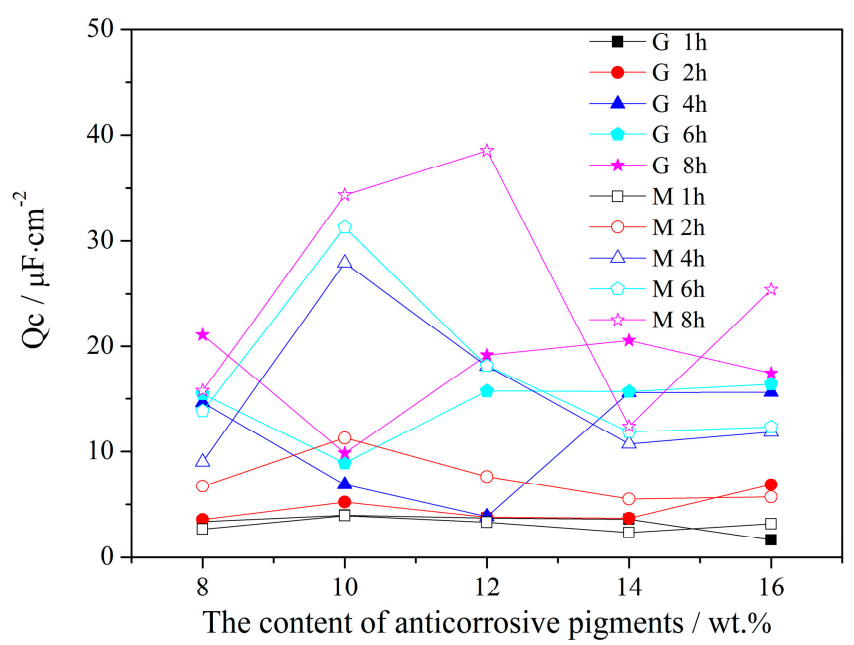

Figure 9. Changes of $Q_{c}$ with time.

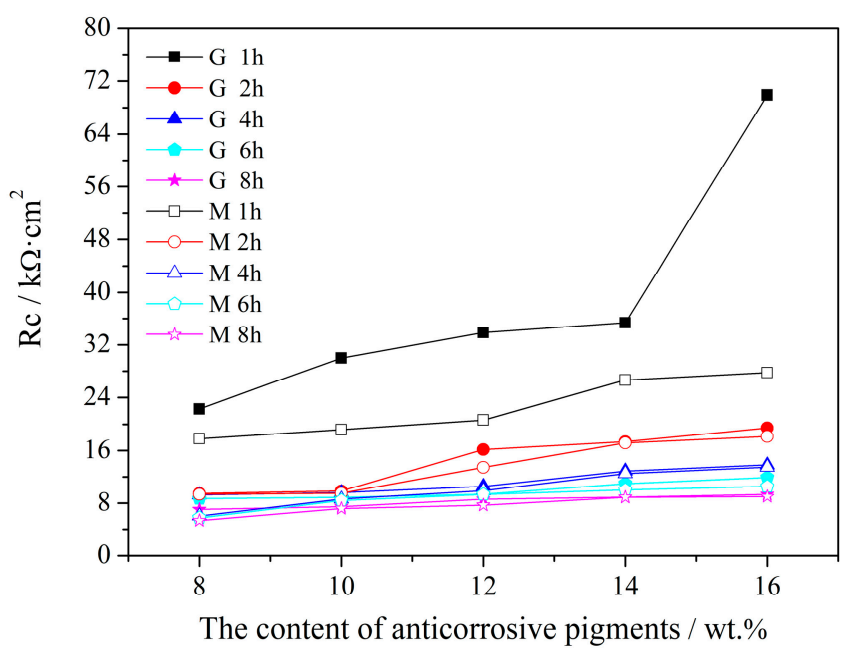

Figure 10. Changes of $R_{c}$ with time.

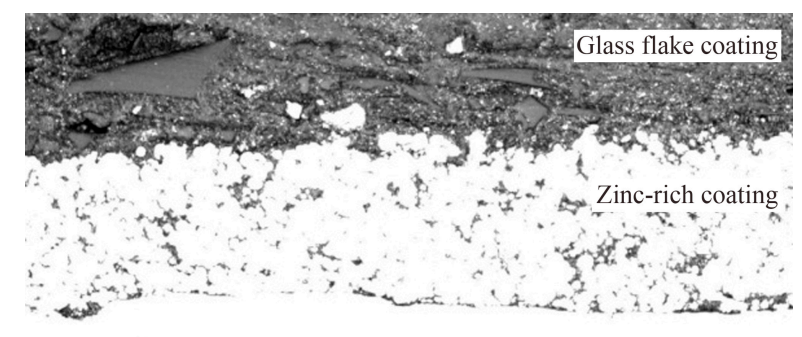

Substrate

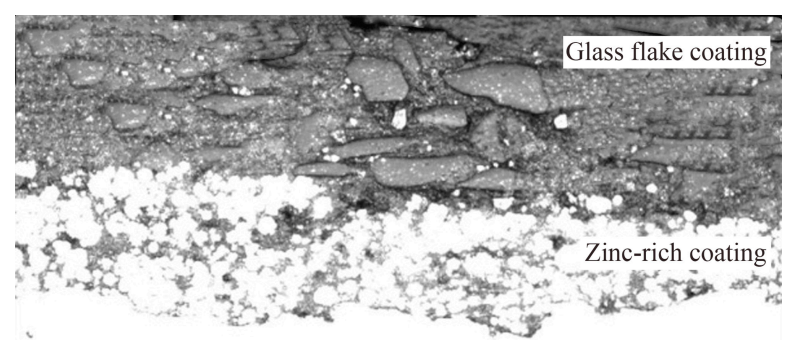

Substrate

(a)

(b)

Figure 11. Cross section images of coatings (a) Z5 + G8 and (b) Z5 + G14. 


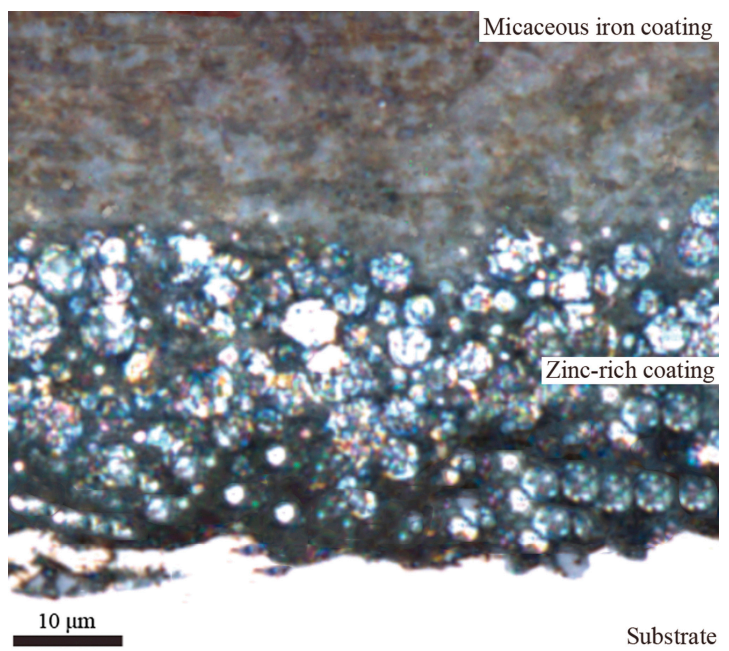

(a)

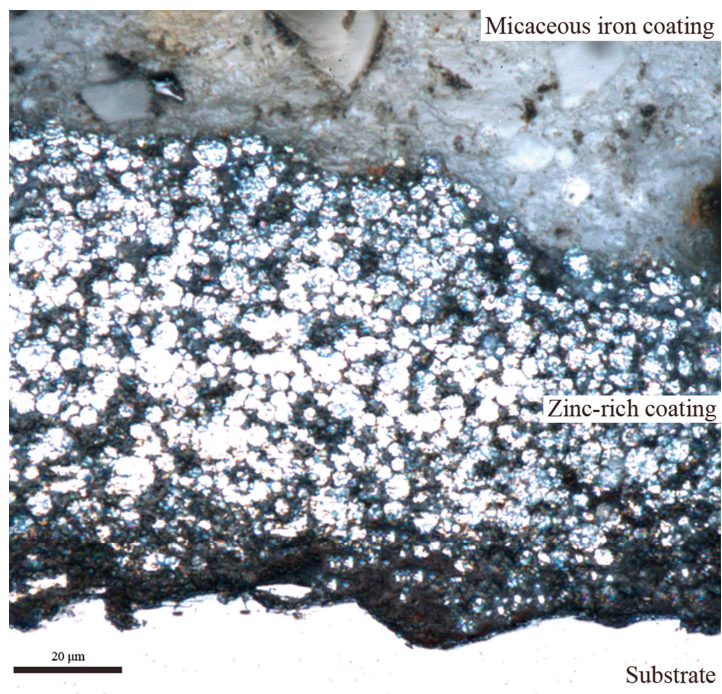

(b)

Figure 12. Cross section images of coatings (a) Z5 + M10 and (b) Z5 + M14 [43].

\section{Conclusions}

In this paper, waterborne silicate anticorrosion coatings and composite coatings composed of antirust and anticorrosion coatings were prepared, and their properties were investigated. The conclusions are as follows:

- For waterborne silicate paints the curing mechanism was modified. Silicate paints form orthosilicates rather than silicates during the curing process.

- For anticorrosion coatings, the adhesion and impact strength reached Grade 1 and $50 \mathrm{~kg} \cdot \mathrm{cm}$, and the pencil hardness could reach $4 \mathrm{H}$-properties which meet the application requirements of marine anticorrosion coatings.

- $\quad$ There was only one time constant during the EIS tests and no corrosion was observed for the $168 \mathrm{~h}$ salt spray, which indicates that the composite coatings possess good corrosion resistance. Due to the large radius-thickness ratio and low density of GF, the GF composite coatings have better corrosion resistance than the $\mathrm{MIO}$ composite coatings.

Author Contributions: Conceptualization, X.Z., Y.Q. and Z.Z.; methodology, X.Z., Y.Q. and Z.Z.; software, X.Z.; validation, K.L.; formal analysis, X.Z. and Z.Z.; investigation, X.Z. and Z.Z.; resources, Y.Q. and Z.Z.; data curation, X.Z.; writing-original draft preparation, X.Z.; writing-review and editing, X.Z., Z.Z. and Y.Q.; visualization, X.Z. and K.L.; supervision, Z.Z. and Y.Q.; project administration, Z.Z. and Y.Q.; funding acquisition, Z.Z. and Y.Q.

Funding: This research was funded by Project of Equipment Pre-research Field Fund, grant number 61409220304 and Equipment Pre-research Sharing Technology Project, grant numbers 41404010306 and 41423060314.

Conflicts of Interest: The authors declare no conflict of interest. 


\section{Appendix A}

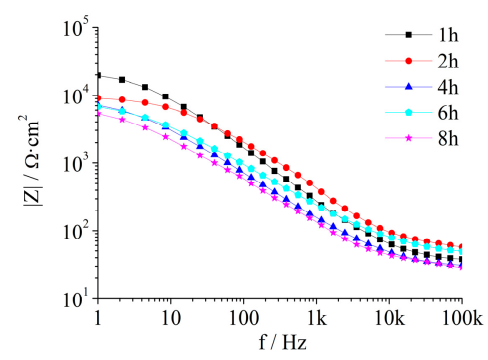

(a)

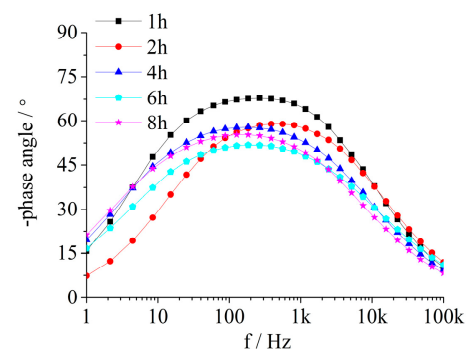

(b)

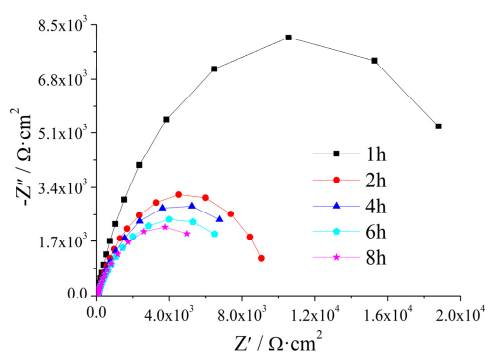

(c)

Figure A1. Bode (a,b) and Nyquist (c) plot of Z5 + G8 in 3.5\% NaCl.

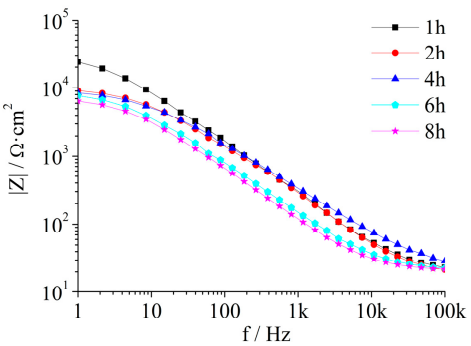

(a)

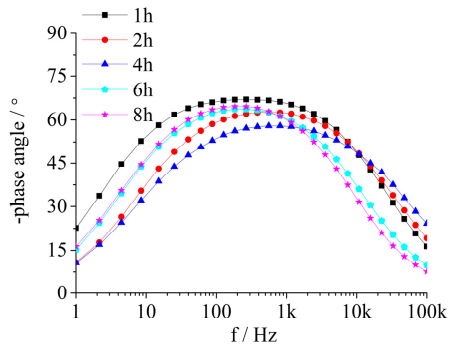

(b)

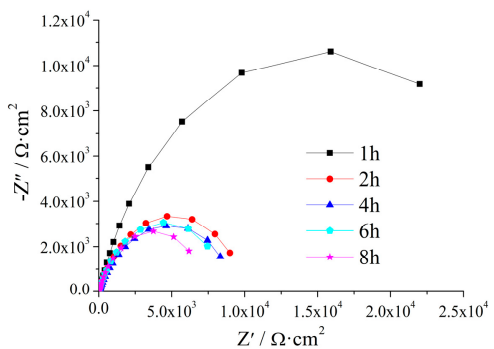

(c)

Figure A2. Bode (a,b) and Nyquist (c) plot of Z5 + G10 in 3.5\% NaCl.

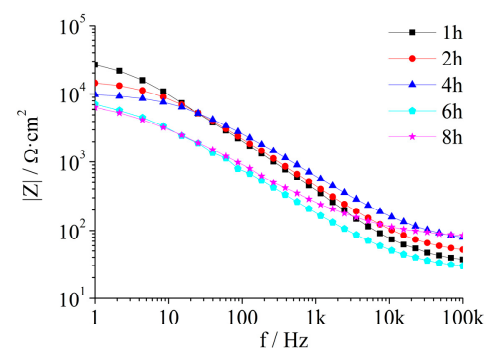

(a)

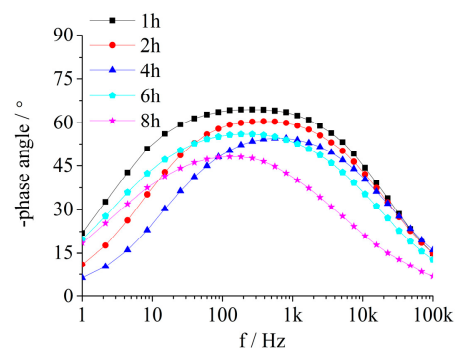

(b)

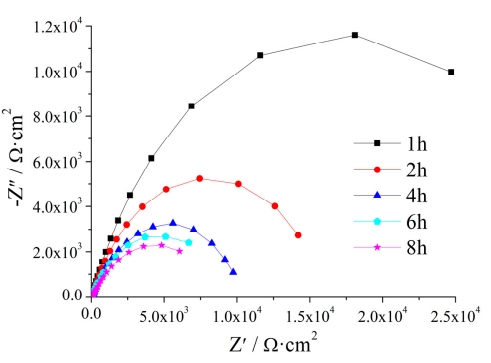

(c)

Figure A3. Bode (a,b) and Nyquist (c) plot of Z5 + G12 in $3.5 \% \mathrm{NaCl}$.

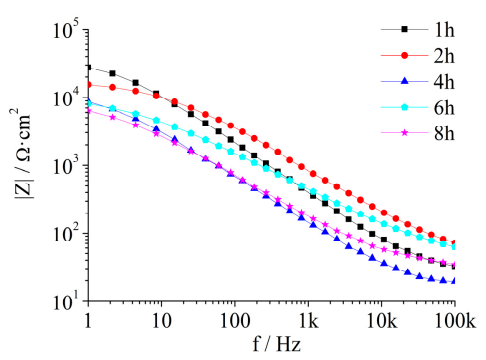

(a)

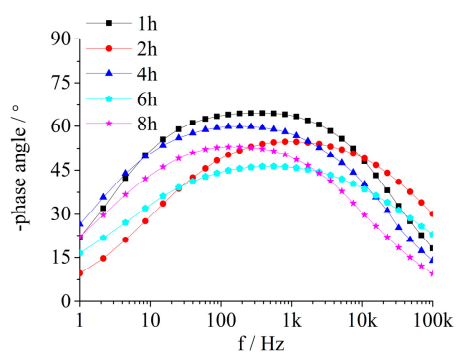

(b)

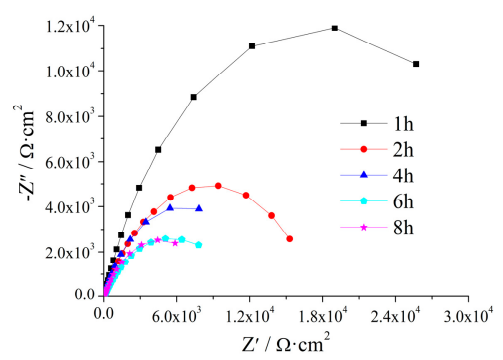

(c)

Figure A4. Bode (a,b) and Nyquist (c) plot of Z5 + G14 in 3.5\% NaCl. 


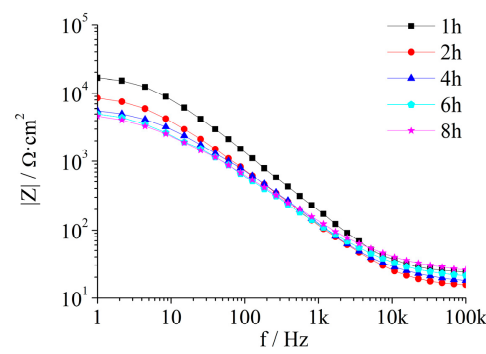

(a)

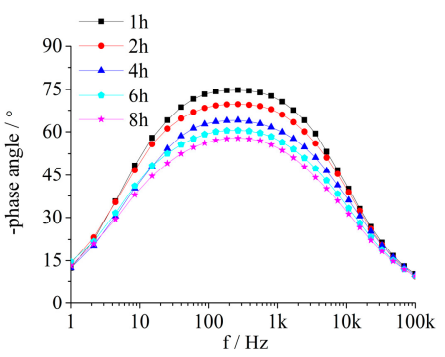

(b)

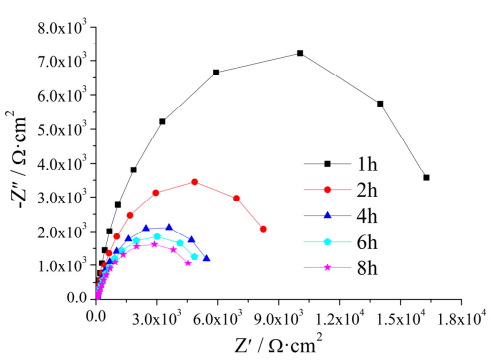

(c)

Figure A5. Bode $(\mathbf{a}, \mathbf{b})$ and Nyquist (c) plot of Z5 + M8 in 3.5\% NaCl.

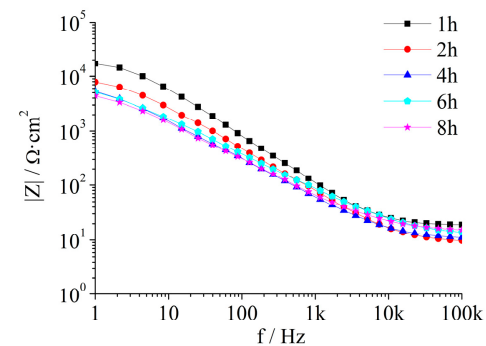

(a)

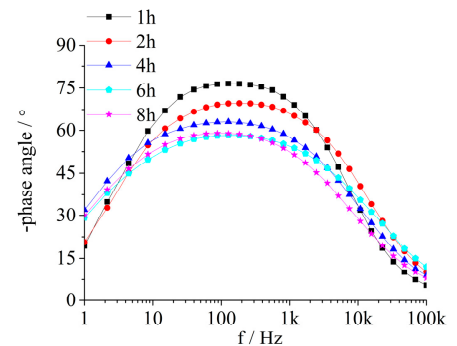

(b)

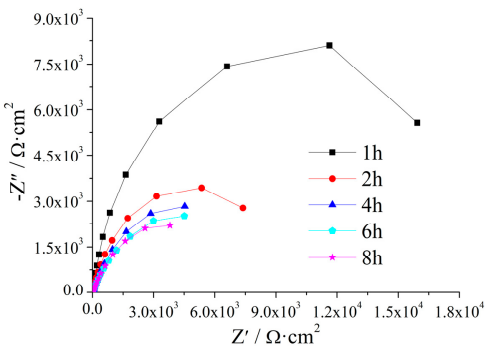

(c)

Figure A6. Bode (a,b) and Nyquist (c) plot of Z5 + M10 in 3.5\% NaCl.

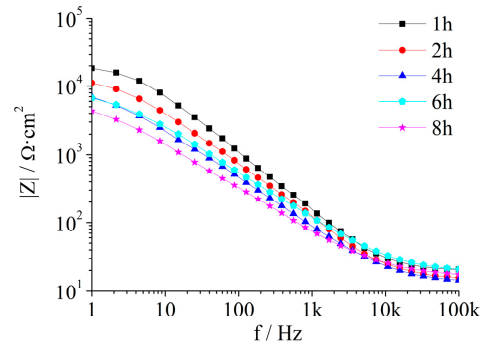

(a)

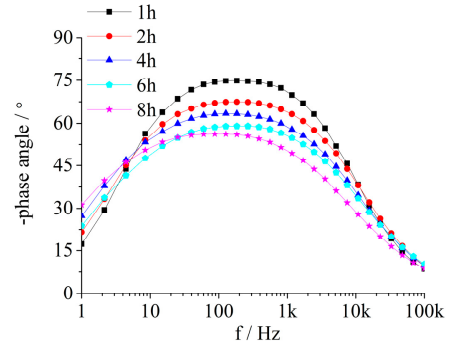

(b)

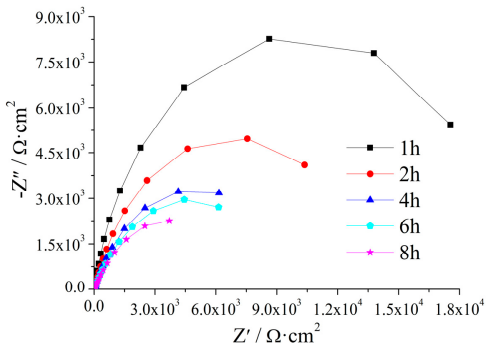

(c)

Figure A7. Bode (a,b) and Nyquist (c) plot of Z5 + M12 in $3.5 \% \mathrm{NaCl}$.

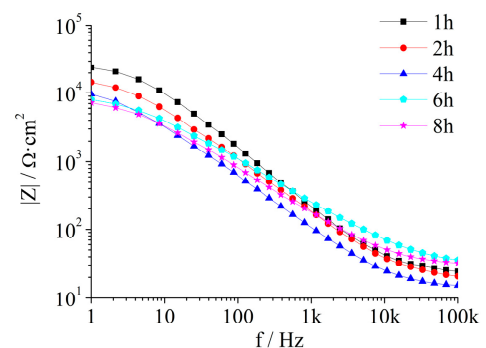

(a)

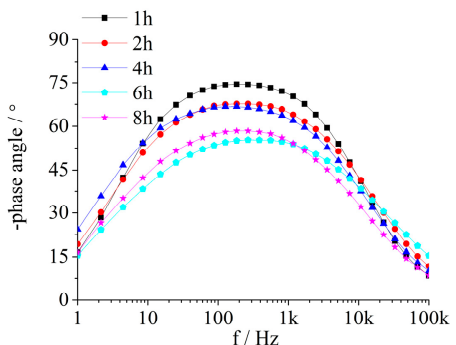

(b)

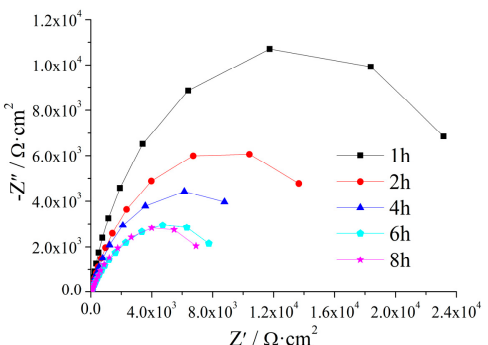

(c)

Figure A8. Bode (a,b) and Nyquist (c) plot of Z5 + M14 in $3.5 \% \mathrm{NaCl}$.

\section{References}

1. Fotovvati, B.; Namdari, N.; Dehghanghadikolaei, A. On coating techniques for surface protection: A review. J. Manuf. Mater. Process. 2019, 3, 28. [CrossRef]

2. Schuerz, S.; Fleischanderl, M.; Luckeneder, G.H.; Preis, K.; Haunschmied, T.; Mori, G.; Kneissl, A.C. Corrosion behaviour of $\mathrm{Zn}-\mathrm{Al}-\mathrm{Mg}$ coated steel sheet in sodium chloride-containing environment. Corros. Sci. 2009, 51, 2355-2363. [CrossRef]

3. Nishimura, K.; Shindo, H.; Kato, K.; Morimoto, Y. Microstructure and Corrosion Behavior of Zn-Mg-Al hot-dip Galvanized Steel Sheet. In Proceedings of the Galvatech '98, Chiba, Japan, 20-23 September 1998; pp. 437-442. 
4. Schürz, S.; Luckeneder, G.H.; Fleischanderl, M.; Mack, P.; Gsaller, H.; Kneissl, A.C.; Mori, G. Chemistry of corrosion products on $\mathrm{Zn}-\mathrm{Al}-\mathrm{Mg}$ alloy coated steel. Corros. Sci. 2010, 52, 3271-3279. [CrossRef]

5. Keppert, T.A.; Luckeneder, G.; Stellnberger, K.H.; Mori, G.; Antrekowitsch, H. Investigation of the corrosion behavior of Zn-Al-Mg hot-dip galvanized steel in alternating climate tests. Corrosion 2014, 70, 1238-1248. [CrossRef]

6. Keppert, T.A.; Luckeneder, G.; Stellnberger, K.H.; Mori, G.; Antrekowitsch, H. The effect of sulphate, phosphate, nitrate and acetate on the corrosion behaviour of $\mathrm{ZnAl}-\mathrm{Mg}$ hot-dip galvanised steel. Mater. Corros. 2014, 65, 560-568. [CrossRef]

7. Lebozec, N.; Thierry, D.; Peltola, A.; Luxem, L.; Luckeneder, G.; Marchiaro, G.; Rohwerder, M. Corrosion performance of $\mathrm{Zn}-\mathrm{Mg}-\mathrm{Al}$ coated steel in accelerated corrosion tests used in the automotive industry and field exposures Mater. Mater. Corros. 2013, 64, 969-978. [CrossRef]

8. Bobzin, K.; Oete, M.; Linke, T.F.; Schulz, C. Corrosion of wire arc sprayed ZnMgAl. Mater. Corros. 2015, 66, 520-526. [CrossRef]

9. Duchoslav, J.; Truglas, T.; Groiß, H.; Riener, C.K.; Stifter, D. Structure and chemistry of surface oxides on ZnMgAl corrosion protection coatings with varying alloy composition. Surf. Coat. Technol. 2019, 368, 51-58. [CrossRef]

10. Li, Z.W.; Wang, H.P. Analysis on the situation and prospect of china anticorrosion coatings industry. China Paint 2012, 27, 17-20. (In Chinese)

11. Cheng, L.H.; Liu, C.L.; Han, D.J.; Ma, S.H.; Guo, W.H.; Cai, H.F.; Wang, X.H. Effect of graphene on corrosion resistance of waterborne inorganic zinc-rich coatings. J. Alloys Compd. 2019, 774, 255-264. [CrossRef]

12. Jolin, W.C.; Oster, C.; Kaminski, M.D. Silicate coating to prevent leaching from radiolabeled surrogate far-field fallout in aqueous environments. Chemosphere 2019, 222, 106-113. [CrossRef]

13. Castro, Y.; Duran, A. Control of degradation rate of $\mathrm{Mg}$ alloys using silica sol-gel coatings for biodegradable implant materials. J. Sol-Gel Sci. Technol. 2019, 90, 198-208. [CrossRef]

14. Guo, L.L.; Tao, X.; Gong, Z.; Guo, A.R.; Du, H.Y.; Liu, J.C. Preparation of $\mathrm{MoSi}_{2}-\mathrm{SiC}_{-}-\mathrm{Al}_{2} \mathrm{O}_{3}-\mathrm{SiO}_{2}$ coating on mullite fibrous insulation with silica sol as binder by non-firing process. Ceram. Int. 2019, 45, 2602-2611. [CrossRef]

15. Sayyedan, F.S.; Enayati, M.H. On structure and oxidation behaviour of non-stoichiometric amorphous aluminium phosphate coating. Surf. Eng. 2019, 35, 670-676. [CrossRef]

16. Mokabber, T.; Zhou, Q.; Vakis, A.I.; van Rijn, P.; Pei, Y.T. Mechanical and biological properties of electrodeposited calcium phosphate coatings. Mater. Sci. Eng. C Mater. Biol. Appl. 2019, 100, 475-484. [CrossRef]

17. Zheng, S.X.; Li, J.H. Inorganic-organic sol gel hybrid coatings for corrosion protection of metals. J. Sol-Gel Sci. Technol. 2010, 54, 174-187. [CrossRef]

18. Narita, T.; Kikuchi, N.; Kawasaki, K.; Ozaki, Y. Preparation and characterization of phenol resin coatings containing silica. J Ceram. Soc. Jpn. 1996, 104, 504-509. [CrossRef]

19. Peng, G.Y. Preparation and Properties of Waterborne Inorganic Coatings with Potassium Silicate/Silica Sol as Film-Forming Substance. Master's Thesis, South China University of Technology, Guangzhou, China, 2012. (In Chinese).

20. Zhang, S.M. Application of silica sol in environmentally friendly coatings. Urban Roads Bridges Flood Control 2011, 248-249. (In Chinese)

21. Feng, L.; Liu, N.X.; Duan, S.X.; Liu, H. Research on inorganic heat-resisting coating with water solubility. Jiangsu Coal 2002, 3, 28-29. (In Chinese)

22. Zhang, F. Study on Preparation, Performance and Corrosion Mechanism of Anticorrosive Coatings. Ph.D. Thesis, Beijing University of Chemical Technology, Beijing, China, 2007. (In Chinese).

23. Zhao, X.; Zhang, Z.Z.; Zhang, J.T.; Ding, G.Q. Research and development trend of environmentally friendly anticorrosive and antifouling coatings for hulls. Shanghai Coat. 2017, 55, 24-28. (In Chinese)

24. Haas, K.H.; Ambergschwab, S.; Rose, K. Functionalized coating materials based on inorganic-organic polymers. Thin Solid Films 1999, 351, 198-203. [CrossRef]

25. Sang, I.S.; Kim, J.H.; Choi, K.H.; Hwang, Y.Y. Preparation of corrosion protective coatings on galvanized iron from aqueous inorganic-organic hybrid sols by sol-gel method. Surf. Coat. Technol. 2006, 200, 3468-3472.

26. Rosero-Navarro, N.C.; Pellice, S.A.; Castro, Y.; Aparicio, M.; Durán, A. Improved corrosion resistance of AA2024 alloys through hybrid organic-inorganic sol-gel coatings produced from sols with controlled polymerisation. Surf. Coat. Technol. 2009, 203, 1897-1903. [CrossRef] 
27. Wang, Z.; Han, E.; Liu, F.; Qian, Z.; Zhu, L. Waterborne epoxy nanocoatings modified by nanoemulsions and nanoparticles. J. Mater. Sci. Technol. 2014, 30, 1036-1042. [CrossRef]

28. Sathiyanarayanan, S.; Azim, S.S.; Venkatachari, G. Corrosion protection coating containing polyaniline glass flake composite for steel. Electrochim. Acta 2008, 53, 2087-2094. [CrossRef]

29. Yang, C.; Smyrl, W.H.; Cussler, E.L. Flake alignment in composite coatings. J. Membr. Sci. 2004, 231, 1-12. [CrossRef]

30. González-Guzmán, J.; Santana, J.J.; González, S.; Souto, R.M. Resistance of metallic substrates protected by an organic coating containing glass flakes. Prog. Org. Coat. 2010, 68, 240-243. [CrossRef]

31. Arman, S.Y.; Ramezanzadeh, B.; Farghadani, S.; Mehdipour, M.; Rajabi, A. Application of the electrochemical noise to investigate the corrosion resistance of an epoxy zinc-rich coating loaded with lamellar aluminum and micaceous iron oxide particles. Corros. Sci. 2013, 77, 118-127. [CrossRef]

32. Wang, G.; Yang, J. Influences of glass flakes on fire protection and water resistance of waterborne intumescent fire resistive coating for steel structure. Prog. Org. Coat. 2011, 70, 150-156. [CrossRef]

33. Giúdice, C.A.; Benítez, J.C. Optimising the corrosion protective abilities of lamellar micaceous iron oxide containing primers. Anticorros. Methods Mater. 2000, 47, 226-232. [CrossRef]

34. Sørensen, P.A.; Kiil, S.; Dam-Johansen, K.; Weinell, C.E. Anticorrosive coatings: A review. J. Coat. Technol. Res. 2009, 6, 135-176. [CrossRef]

35. Yan, G.; Wang, M.Y.; Sun, T.; Li, X.P. Anti-Corrosion property of glass flake reinforced chemically bonded phosphate ceramic coatings. Materials 2019, 12, 2082. [CrossRef] [PubMed]

36. Naser Kakaei, M.; Danaee, I.; Zaarei, D. Evaluation of cathodic protection behavior of waterborne inorganic zinc-rich silicates containing various contents of MIO pigments. Anticorros. Methods Mater. 2013, 60, 37-44. [CrossRef]

37. Dehghanghadikolaei, A.; Ibrahim, H.; Amerinatanzi, A.; Hashemi, M.; Moghaddam, N.S.; Elahinia, M. Improving corrosion resistance of additively manufactured nickel-titanium biomedical devices by micro-arc oxidation process. J. Mater. Sci. 2019, 54, 7333-7355. [CrossRef]

38. GB/T 1720-1979. Method of Test for Adhesion of Paint Films; China Petroleum and Chemical Industry Federation: Beijing, China, 1980.

39. GB/T 6739-2006. Paints and Varnishes-Determination of Film Hardness by Pencil Test; China Petroleum and Chemical Industry Federation: Beijing, China, 2007.

40. GB/T 1732-1993. Determination of Impact Resistance of Film; China Petroleum and Chemical Industry Federation: Beijing, China, 1993.

41. ASTM B117. Standard Practice for Operating Salt Spray (Fog) Apparatus; ASTM International: West Conshohocken, PA, USA, 2017.

42. Qi, Y.H.; Zhang, Z.P.; Miao, M.; Zhang, X.Z. Studies on estimating methods of polarization performance for coated steel in seawater. Mater. Sci. Forum 2010, 654-656, 2418-2421. [CrossRef]

43. Zhao, X.; Qi, Y.H.; Zhang, Z.P.; Li, K.J. Electrochemical impedance spectroscopy investigation on the corrosive behaviour of waterborne silicate micaceous iron oxide coatings in seawater. Coatings 2019, 9, 415. [CrossRef]

44. Wang, P.; Yang, Q.; Cheng, X.R. Study on the curing mechanism of sodium silicate inorganic zinc-rich coating. Appl. Chem. Ind. 2007, 36, 1076-1080.

45. Zhou, C.J. Preparation of Silicate Waterborne Inorganic Zinc-Rich Anticorrosion Coatings and Studies on its Performance. Master's Thesis, Shenyang University of Technology, Shenyang, China, 2014. (In Chinese).

46. Ding, J.H.; Liu, S.; Gu, L.; Zhao, H.C.; Yu, H.B. Corrosion resistance of epoxy phosphate/waterborne epoxy coatings on steel. China Surf. Eng. 2015, 28, 126-131. (In Chinese)

47. Li, Y.; Yang, Z.; Qiu, H.; Dai, Y.; Zheng, Q.; Li, J.; Yang, J. Self-aligned graphene as anticorrosive barrier in waterborne polyurethane composite coatings. J. Mater. Chem. A 2014, 2, 14139-14145. [CrossRef]

48. Castela, A.S.; Simões, A.M. An impedance model for the estimation of water absorption in organic coatings. Part I: A linear dielectric mixture equation. Corros. Sci. 2003, 45, 1631-1646. [CrossRef]

(C) 2019 by the authors. Licensee MDPI, Basel, Switzerland. This article is an open access article distributed under the terms and conditions of the Creative Commons Attribution (CC BY) license (http://creativecommons.org/licenses/by/4.0/). 